\title{
Part 12. Dental images: Ensuring the understanding, acceptance and consent of and by patients to all possible usages.
}

SADJ August 2017, Vol 72 no 7 p336 - p338

LM Sykes ${ }^{1}$, A Harryparsad², WG Evans ${ }^{3}$

There is an idiom which says "A picture is worth a thousand words". At no time could this be truer than in the very visual digital world of today. The Internet, having the ability to mix text with other media such as pictures and videos, has revolutionized the way information is published and consumed. While it has been estimated that more than $80 \%$ of online activities are text-based, reading large amounts of information is time consuming and can be overwhelming. Thus if these activities can be enhanced by multimedia, or substituted with images, consumer behaviour could be transformed and their behaviour shifted, as well as enhancing learning and interactions with others. $^{1}$

\section{INTRODUCTION}

Dentistry has not escaped this digital explosion, with social media usage and interactions being a part of everyday life for most practitioners and patients. In the clinical setting, photographs, radiographs and scans are taken for many reasons and serve different purposes. They can form part of the dental records to document the "before treatment" situation, to aid communication with colleagues when seeking advice, to show to students in educational settings, to illustrate treatment options to patients, to be available for publishing in dental journals as part of research or case studies, and on internet sites when sharing treatment outcomes with others. ${ }^{2}$ There is an abundance of literature regarding the importance of gaining informed consent before embarking on any dental treatment. The process by which this is obtained is guided and instructed by ethical principles, legal requirements and professional policies. ${ }^{3}$ Surely then, patient images should require the same levels of informed consent and assurance of confidentiality. ${ }^{2}$ The mere act of signing a

1. Leanne M Sykes: BSc, BDS, MDent (Pros), Dip Res Ethics (Irensa), Dip Forensic Odont. Department of Prosthodontics, University of Pretoria.

2. Ashana Harryparsad: BDS, PDD (Interceptive Orthodontics), MDent (Pros). Department of Prosthodontics, University of Pretoria.

3. William G Evans: BDS, Dip Ortho. Department of Orthodontics, University of Witwatersrand.

\section{Corresponding author}

Leanne M Sykes:

Department of Prosthodontics, University of Pretoria.

E-mail: leanne.sykes@up.ac.za consent form is secondary to ensuring that good process has been followed in the process leading up to this written affirmation. Valid consent can only ensue if there has been full disclosure by the dentist, clear understanding by the patient as to the conditions and scope of the agreement, and a shared decision-making process. ${ }^{4}$

This paper will discuss the requirements of a valid consent process, and will present a draft patient consent form that may be adapted and used when consent is sought for the use of personal images in dentistry.

\section{REQUIREMENTS FORINFORMED CONSENT}

This can be divided into dentist and patient factors. The National Health Act No 61 (2003) stipulates that the following information must be given to all patients: the range of diagnostic and treatment options available; the benefits, risks, costs and consequences of each; and the implications, risks and consequences if treatment is refused..$^{5}$ In addition, it should be presented in a manner that does not place any undue influence on the patient, allowing time for consideration all the options before the agreement is signed. The process of ensuring understanding, comprehension and agreement or refusal is of prime importance. ${ }^{6}$ During the discussion the clinician can get to know the patient better, listen to all his/ her fears and concerns and tailor the treatment according to the needs and desires. This builds patient trust and confidence and also allows them to feel more in control, which may lead to improved compliance. ${ }^{6}$

There are three key elements involved in the consent process, concerning both the dentist and the patient:

1. Threshold elements entail that the patient is sufficiently competent to understand and decide, and can make the decision voluntarily

2. Information elements relate to the duty of the dentist to disclose all relevant information, to recommend an appropriate plan of action that will serve the patient's best interests and to ensure that the patient has clearly understood all of the information.

3. Consent elements refer to the patient's ability to decide for or against the treatment, and to then authorize the plan of action. ${ }^{7}$ Note: a patient may later withdraw consent provided the condition is not life threatening, and the patient is not ignorant or uninformed. By the 
same token, the dentist does not have to provide any treatment considered to be potentially harmful to the patient. $^{5}$

\section{DIFFERENCES BETWEEN CONSENT TO TREATMENT AND CONSENT TO USE OF PERSONAL INFORMATION / IMAGES}

\section{Consent to treatment}

This requires the dentist to explain the proposed therapy, risks involved, time and cost implications, alternative options and the consequences of no treatment. This should take the form of a verbal discussion followed by written information, which the patient needs time to read and consider. In many instances consent is often "implied" and assumed by inference from the patient's actions even though there was no actual explicit consent process. This may suffice for many routine dental procedures, such as examination and charting but will not provide protection for a dentist against legal actions if more extensive work has been done. ${ }^{3}$

"Expressed" consent is specific, and should be gained from a patient for each particular procedure that is not routine or which carries some form of risk. It may be given in either an oral or written form. The former is valid and may be adequate for minor work, but must still be witnessed and documented in the patient's records. Written consent is required for more extensive treatment. Although this may be used to defend a legal action, it does not automatically mean that the goals of informed consent have been met. $^{3}$ Not only must the dentist

\section{APPENDIX A:}

Patient consent form for the use of dental images

This form provides consent for the use of my dental images, including photographs, radiographs and scans, for either record purposes, as diagnostic aids, for treatment planning, communication with colleagues, teaching and lecturing, in printed or electronic publications, and /or for research subject to the conditions signed for below.

Name of person shown in photograph:

Contact details of clinician:

I___[insert full name] give my consent for this information about MYSELF/MY CHILD OR WARD/MY RELATIVE [circle correct description] relating to the subject matter above to be used for the purposes indicated in Column $\mathrm{A}$, and adhering to the conditions stipulated in Columns B, C and D.

I understand that:

1. The Information will be used or published without my name attached and every attempt will be made to ensure my anonymity. I understand, however, that complete anonymity cannot be guaranteed and there is a remote chance that somebody may be able to identify me.

2. The illustrations may be published in sites that have a local or worldwide distribution. Although this material is aimed at dentists and related medical specialists, it may be seen by other lay persons, including journalists.

3. The illustrations may appear on dental or educational websites which are visited by many different users.

4. My information and illustrations may also be used in full or in part in publications and may be translated in print, in electronic formats, and in any other formats that may be used now and in the future. It may appear locally and internationally.

5. None of my information or illustrations will be used for advertising purposes or used out of context for unrelated purposes.

6. I can withdraw my consent at any time before publication, but once it has been published or posted on the internet I understand that it will not be possible to revoke the consent. Illustrations may be withdrawn but the clinician and publishers have no control over images that have been uploaded and used by others prior to this withdrawal.

Signed:

Date:

Conditions of Acceptance

\section{Image Code \\ - (date \& time)}

\section{Subject matter} description

\begin{tabular}{l|l|l|l}
\hline A. Anticipated use: & B. Can be used & C. Cannot be used & $\begin{array}{l}\text { D. Must first be } \\
\text { viewed \& accepted }\end{array}$ \\
\hline Dental records & & & \\
\hline Diagnostic aids and treatment planning & & & \\
\hline Communication with colleagues & & & \\
\hline Teaching \& Lecturing & & & \\
\hline Publications (print media) & & & \\
\hline Publications (print or electronic media) & & & \\
\hline Research & & & \\
\hline
\end{tabular}


ensure adequate disclosure, provide sufficient necessary information, and refrain from placing any undue influence on the patient, but the patient needs to have the capacity to understand, appreciate the consequences, communicate, weight up various options, and make autonomous choices. ${ }^{4}$ The clinician also needs to be aware that this process involves both the assimilation of information and decision making prior to the actual consent, and that the decision may be to agree or to decline consent. ${ }^{4}$

\section{Consent to use of information and/ or images}

This differs somewhat from consent to treatment and involves clarification of scope and conditions of use. ${ }^{4}$ Here the clinician is required to provide full disclosure, as opposed to the adequate information which is required when seeking to secure consent to treatment. This entails giving sufficient specific information as to how and why the images will be used, who is the potential viewing audience, how much of the patient's details will be shared, and the possible domains where they may appear. ${ }^{2}$ All patient images, regardless of whether or not they will be seen by others or contain identifying features, require the same consent process, guarantees of confidentiality and safeguards as any other medical record. ${ }^{2}$ As with consent for treatment, the person who is being photographed should be the one to provide this consent, or the parent / legal guardian in the case of minors. ${ }^{2}$ However, the latter should still be asked for assent if possible. Consent must be provided for ALL intended uses of each image, even if merely for record purposes. In the case of possible publication, the patient should be made aware that electronic publications have the potential to reach wide audiences and to be re-posted on many internet sites. In addition, once published or posted in a public domain it cannot later be removed. Patients or guardians should also be given a copy of the consent form with contact details of the clinician should they desire to withdraw consent at a later stage. If so, the images can be removed from display in whatever form that may be, however there must be awareness that printed media cannot be retracted, and neither can images that have been downloaded from internet sites and re-used by others. ${ }^{2}$ Patients must also be reassured that they have every right to refuse the use of their images or to ask for withdrawal at a later stage and that this will in no way negatively affect their doctor-patient relationship or treatment.

\section{DRAFT CONSENT FORM}

A draft consent form for use in Dentistry has been developed. This can be adapted and used by clinicians according to their needs (see attachment). The aim was to keep it as clear and straightforward as possible, while at the same time giving patients the opportunity to specify in detail their desires. It makes provision for patients to choose and sign a once-off consent to the taking and use of all images for all or limited purposes (e.g. for records only, for lectures and teaching, in publications), to sign at each appointment for specific use of the images taken that day, or to request the opportunity to view each image before giving approval for its use. In the case of the first options, a once-off consent signature will suffice. For the other choices, patients will have to sign each block on the second page at each visit. This page can easily be duplicated as many times as needed. In all instances anonymity and protection of identity must be guaranteed.
At the same time the clinician should ensure that public use of images does not disclose enough personal information that would allow a third party to put the pieces together and to identify the patient. ${ }^{8}$

The option of choice should be clearly marked on the front of the record files to alert the clinician that consent may be needed each time a photograph is taken. Each image must also be clearly identified in the consent form. A good way to do this while still ensuring anonymity would be to code it using the date and time of capture, as these numbers will never be duplicated and are easy to collate with the files if accurate appointment books are kept.

\section{CONCLUSIONS}

Adaption of a specific image consent form will enhance the patient's trust of the patients in their dentists, and will help safeguard clinicians when they make use of these images, privately or publically for professional purposes. It also reinforces the principle of "Veracity" or truthfulness which relates to the concept that "professionals have a duty to be honest and trustworthy in their dealings with patients, including respecting the position of trust inherent in the dentist-patient relationship, communicating truthfully and without deception, and maintaining intellectual integrity at all times". ${ }^{9}$

\section{References}

1. Wired.com. As It Turns Out, a Picture Is Not Worth a Thousand Words. Accessed at: https://www.wired.com/.../2014/03/ turns-picture-worth-thousand-words; Accessed on 01-032017.

2. Cunniff $C$, Byrne JLB, Hudgins $L M$, et al. Informed consent for medical photographs. Genet Med. 2000;2(6):353-5.

3. Tahir MAM, Mason C, Hind V. Informed consent: optimism versus reqality. Br Dent J. 2002;193:221-4.

4. van Staden CW. Informed Consent to Treatment. Oxford, editor: Oxford; 2015.

5. Naidoo S, Moodley, K. Ethics and the Dental Team. Schaik V, editor. Hatfield, Pretoria: Van Schaik; 2009. 136.

6. Zion D, Gillam, L, Loff, B. The Declaration of Helsinki, CIOMS and the ethics of research on vulnerable populations. Nature Medicine. 2000;6(6):615-7.

7. Beauchamp T, Childress, JF. Principles of Biomedical Ethics. Oxford University Press, New York: 2001.

8. Pillai R. Continuous Care. Accessed at: www.continuouscare. io/healthcare-marketing-ethics-for-physicians-medicalpractices2016; Accessed on : 01-03-2017.

9. ADA. Section 5 - Principle of Veracity ("Truthfulness") Accessed at: http://www.ada.org/en/about-the-ada/principles-of-ethicscode-of-professional-conduct/veracity; Accessed on: 24-102016. 